\title{
Reorganization of Spanish science policy gets under way
}

\section{Barcelona}

AN important step has been taken towards setting in train the reforms in Spanish science policy under the Science Law approved last year (see Nature 324, 316$317 ; 1986)$. The latest decisions confirm the intention of the socialist government to build up a new and better orientated organization of science policy centred around the national plan for scientific research and development.

In recent weeks, the new structure for the organization of science policy has been published and appointments have been made to the principal posts. The Science Law assigns the preparation of the national plan for research to an interministerial commission on which are represented the departments interested in

\section{New UK technology centres launched \\ London}

SEVEN regional technology centres are to be created in Britain, financed by a $£ 1,548$ million first-year budget provided jointly by government, industry and academic institutions to bring together the relevant partners interested in commercially exploiting technology.

A fund of $£ 687,000$ will be derived from government coffers while 22 universities, 14 polytechnics and 17 partners in industry, including GEC, Ferranti, RollsRoyce, British Aerospace and British, will provide the rest. According to Mr Kenneth Baker, Secretary of State for Education and Science" "We are now pressing ahead with an initial seven centres which will build on existing successful schemes to transfer technological innovation from the laboratory into new products for business and industry. More centres will follow later... Whilst enabling business to capitalize on the opportunities created by new research developments, the close ties with education should foster a closer relationship between undergraduates, diploma and continuing education courses and the world of work."

The government funds, up to about $£ 100,000$ a centre for the first year, will help establish the network, with funding reducing in the second year as the centres move towards self-financing. The industrial and higher-education partners will provide the rest of the cash, equipment and personnel to operate the centres.

Typically, the centres will offer these services in manufacturing technology, biotechnology, computers and microelectronics, information technology and materials.

Bill Johnstone research. The key appointment is that of Dr Emilio Muhoz as secretary general of the plan, attached to the ministry of education and science.

Muhoz, a biochemist, has been director general of science policy since the socialist government came to power in 1982 and is one of those responsible for the new law. In addition to preparation of the plan, he will deal with other matters such as the coordination of international activities and will have several technical departments at his disposal intended to create an administrative structure to assist decisionmaking in science policy.

The new director general of science policy is Dr Luis Oro, an inorganic chem-

\section{Germans build synchrotron}

Munich

WEST Germany wants to fill a gap in the spectrum of facilities for "medium-energy physics" with a device called COSY. A cooled synchrotron, COSY is a proton accelerator that will be used to conduct experiments at kinetic energies of 2.5 $\mathrm{GeV}$ that higher-energy installations such as CERN (the European Organisation for Nuclear Research) have neglected. The results are expected to reveal more about phenomena such as the creation and decay of strange baryons and mesons.

COSY will be constructed at Kernforschungsanlage (Nuclear Research Institute or KFA) at Jülich and should be completed by 1992 . Ninety per cent of the estimated cost of DM90 million will be assumed by the Federal Ministry for Research and Technology.

A storage synchrotron with phasespace cooling, COSY will offer a unique feature for such synchrotrons: a very narrow proton beam. Although it will not offer the same beam intensity as its French predecessor, the Saturn Ring at Saclay $\left(10^{16)}\right.$ protons $\mathrm{s}^{-1}$ compared with Saturn's $10^{11}$ protons $\left.\mathrm{s}^{-1}\right)$, COSY's beam width of about $0.5 \mathrm{~mm}$ will permit observations of various collisions. The Saturn Ring, by comparison, has a beam width of 3-4 mm.

Shaped like a racetrack, COSY will use one of the KFA's accelerators as an injector. Targets may be placed within the racetrack and outside it, and sensitive spectrometers are also available to observe the meson 'sparks' from each collision.

But a detector has yet to be built at the KFA that can measure the most energetic elastic collisions. Such a spectrometer, said scientific director Kurt Kilian, "will come sooner or later". Steven Dickman ist from the University of Zaragoza who was an official in the Comision Asesora de Investigacion Cientifica y Tecnica (CAICYT), the main granting body for research in the previous system.

An interesting new body created as part of the reorganization now under way is the national agency for evaluation and forecasting. This is meant to be an independent body for the evaluation of grant applications and is intended to continue the policy of the former CAICYT. The new agency will probably be based on the experience already acquired by CAICYT.

Pedro Puigdoménech

\section{International acid rain protocol hopes}

\section{London}

Agreement on the contents for a protocol on the so-called international acid rain treaty is coming closer, as representatives met this week in Geneva for another round of negotiations. A limit on emissions and deposition of nitrogen oxides is the goal of the United Nations/Economic Commission for Europe UN/ECE working party, set up as a result of the 1979 Convention on LongRange Transboundary Air Pollution.

Previous meetings of the working party have been acrimonious, largely because of opposition to a nitrogen-oxides protocol by Britain and Eastern European countries. Now, however, the first proposals for a protocol have been agreed, centring on a phased approach to controls.

This week's negotiations will focus on measures to be taken during each phase, and the setting of "critical load targets" for nitrogen-oxide depositions. The concept of critical load - "the highest load which will not cause chemical changes leading to longterm harmful effects on the most sensitive ecological systems" - now seems generally accepted as a more scientific approach than the politically based 30-per-cent reduction set in a similar protocol on sulphur emissions. Critical load targets could be achieved by specifying a percentage reduction in emissions and transboundary fluxes, and/or by technical standards specifying measures to be taken.

Non-governmental organizations attending the meetings have been calling for an overall reduction of 75 per cent, with a limit on nitrogen oxides deposition of less than $10 \mathrm{~kg}$ per hectare per year.

Kathy Johnston

Britain's Central Electricity Generating Board (CEGB) last week announced plans for a 10-year programme to install low nitrogen-oxide burners at 12 major coalfired power stations. The retro-fitting programme, which is expected to begin in 2-3 years, will lead to a reduction in nitrogenoxide emissions of nearly 30 per cent on 1980 levels, according to the CEGB. 